\title{
Centrifuge Modelling of Flexible Retaining Walls Subjected to Dynamic Loading.
}

Michele Tricarico.

Dipartimento di Ingegneria, Università degli Studi di Napoli Parthenope, Napoli, Italy. Centro Direzionale isola C4, 80143 Napoli, Italy. Permanent adress: via Mascagni 14, Ruvo di Puglia, 70037 Bari, Italy. E-mail: michele.tricarico159 @gmail.com.

Gopal Santana Phani Madabhushi.

Engineering Department, University of Cambridge, UK. Schofield Centre, High Cross Road, Cambridge, Cambs CB3 0EL. E-mail: mspg1@cam.ac.uk.

Stefano Aversa.

Dipartimento di Ingegneria, Università degli Studi di Napoli Parthenope, Napoli, Italy. Centro Direzionale isola C4, 80143 Napoli, Italy. Email: aversa@uniparthenope.it.

\section{Abstract}

This paper outlines the results of an experimental program carried out on centrifuge models of cantilevered and propped retaining walls embedded in saturated sand. The main aim of the paper is to investigate the dynamic response of these structures when the foundation soil is saturated by measuring the accelerations and pore pressures in the soil, displacements and bending moment of the walls. A comparison among tests with different geometrical configurations and relative density of the soil is presented. The centrifuge models were subjected to dynamic loading in the form of sinusoidal accelerations applied at the base of the models. This paper also presents data from pressure sensors used to measure total earth pressure on the walls. Furthermore, these results are compared with previous dynamic centrifuge tests on flexible retaining walls in dry sand.

\section{INTRODUCTION}

The study and the monitoring of earth retaining structures [1, 2, 3, 4] and of physical models in centrifuge simulations $[5,6,7,8,9,10,11,12]$ have shown the vulnerability of these structures during seismic events.

The presence of water affects the dynamic response of such structures mainly for three reasons: influence on the effective stresses of pore pressures due to the presence of water in hydrostatic or permanent flow state, secondly hydrodynamic pressures acting directly on the structure and finally modification of earth pressure due to variation of pore water pressure produced by seismic action in undrained conditions. The latter aspect can also determine the occurrence of liquefaction, which, besides the structural failure and the mobilisation of shear strength, is another relevant cause of collapse of retaining structures. While for the first two factors some simplified solutions can be used, like the generalized apparent angle of seismic coefficient [13] and the Westergaard solution [14], the calculation of the pore pressure build up during the shaking is related to the material response to the dynamic cyclic loading and is very difficult to predict [15]. From a theoretical point of view, this problem can be analysed through the implementation of adequately complex constitutive laws, to be used within a software that solves numerically the Biot's coupled twophase equations that describe the mechanical response of the soil-structure system. From an experimental point of view physical models can certainly represent a tool to help observe the dynamic behaviour of saturated soil in the far-field and in proximity of a structure. In addition, they offer the possibility to verify the capability of prediction of the numerical analyses. 
This work aims at developing an understanding of the dynamic behaviour of flexible retaining walls embedded in saturated sand. An experimental program consisting of a series of dynamic centrifuge tests has been carried out at the Schofield Centre of the University of Cambridge (UK) with the aim of studying the dynamic response of these structures. The tests have been performed on reduced scale models of pairs of retaining walls, both cantilevered and with one level of props near the top of the wall. The main objective of this work is to investigate the mechanisms affecting the seismic behaviour of these structures in the presence of ground water.

\section{GEOMETRIES OF THE MODELS}

The experimental campaign consisted of seven tests on embedded walls in saturated sand, with piezometric head at dredge level (see Figure 1). Four tests have been carried out on pairs of cantilevered walls (CWU1, CWU2, CWU3 and CWU4), and three tests on models of propped walls (PWU1, PWU2 and PWU3). Preliminary results of some of the tests (CWU1, PWU1, CWU2 and PWU3) have been already described by Aversa et al. (2015). A centrifugal acceleration equal to $40 \mathrm{~g}$ has been selected. Table 1 reports the main geometrical properties at the prototype scale with model scale dimensions in $\mathrm{mm}$ shown in brackets. The total height of the walls is $200 \mathrm{~mm}$ at the model scale, corresponding to $8 \mathrm{~m}$ at the prototype scale. The excavation depths are of $90 \mathrm{~mm}$ and $140 \mathrm{~mm}$ at the model scale for tests CWU and PWU corresponding to $3.6 \mathrm{~m}$ and $5.6 \mathrm{~m}$ at the prototype scale. In particular, the total height of the walls, the excavation depth and the embedment depth, $d$, are similar to those already adopted in a previous experimental work on retaining walls in dry sand $[6,7]$, in order to isolate the effects of the saturation condition on the dynamic behaviour of this type of structures. Two different relative densities (38\% and $80 \%$ ) have been chosen, to study the effect of relative density on the structural response.
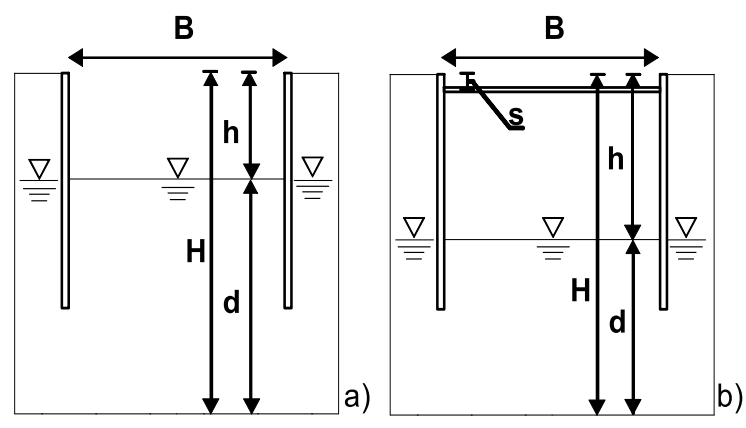

Fig. 1. Reference models and geometrical features: (a) tests CWU on cantilevered walls and (b) tests PWU on propped walls.

\begin{tabular}{|c|c|c|c|c|c|}
\hline \multicolumn{2}{|c|}{} & \multicolumn{5}{|c|}{ Prototype scale (m) } \\
(Model scale) (mm) \\
\hline Test & $\begin{array}{c}\mathrm{D}_{\mathrm{R}} \\
(\%)\end{array}$ & $h$ & $d$ & $S$ & $B$ \\
\hline CWU1 & 38 & 3.6 & 4.4 & - & 8 \\
& & $(90)$ & $(110)$ & & $(200)$ \\
\hline CWU2 & 80 & 3.6 & 4.4 & - & 8 \\
& & $(90)$ & $(110)$ & & $(200)$ \\
\hline CWU3 & 80 & 3.6 & 4.4 & - & 8 \\
\hline
\end{tabular}




\begin{tabular}{|c|c|c|c|c|c|}
\hline & & $(90)$ & $(110)$ & & $(200)$ \\
\hline CWU4 & 80 & 3.6 & 4.4 & - & 8 \\
& & $(90)$ & $(110)$ & & $(200)$ \\
\hline PWU1 & 38 & 5.6 & 2.4 & 0.45 & 8 \\
& & $(140)$ & $(60)$ & $(9)$ & $(200)$ \\
\hline PWU2 & 80 & 5.6 & 2.4 & 0.45 & 8 \\
& & $(140)$ & $(60)$ & $(9)$ & $(200)$ \\
& & & & & \\
\hline PWU3 & 80 & 5.6 & 2.4 & 0.45 & 8 \\
& & $(140)$ & $(60)$ & $(9)$ & $(200)$ \\
\hline
\end{tabular}

Tab. 1. Geometrical properties at prototype scale (model scale dimensions in $\mathbf{m m}$ are shown in brackets).

The model has been prepared by pouring the sand inside a laminar box container progressively, adding and positioning the instruments and the walls at the chosen depths. The sand has been poured through a sand hopper previously calibrated in order to reach the desired relative density of the sand [16]. The installation procedure of the model wall did not simulate the excavation procedure followed in field scale geotechnical works, in which the walls are installed first and the soil is excavated between the walls. In this research the walls the soil has been pluviated directly behind the walls to form the backfill and in between the two walls to different heights as required, under 1-g laboratory conditions. The centrifuge acceleration has been applied directly on the excavated configuration of the model. In this study the excavation effects are not captured as the model is constructed under $1 \mathrm{~g}$ conditions. Other researchers, such as Ortiz [17], have modelled staged construction by draining out a heavy fluid from the excavated spaced between the walls gradually to simulate staged excavation at high gravity. This procedure is not adopted in this study as the primary focus of this research was to compare the differences in response between cantilevered and propped wall systems. Different kinds of instruments have been used in order to monitor the following physical quantities: i) acceleration of the soil and of the walls, ii) displacements of the soil surface and of the walls, iii) pore water pressures, iv) bending moment generated in the walls, v) axial forces in the props using load cells. The instruments used for the measurements of these physical quantities are respectively: piezoelectric and MEMS-based accelerometers, linear variable displacements transformers (LVDTs), pore pressure transducers (PPTs), strain gauges and load cells (SG). Figures 2 and 3 show respectively the cross section of model CWU1 and model PWU1. In test CWU1 8 miniature piezoelectric accelerometers (Acc), 4 LVDTs for horizontal displacements, 2 LVDTs for surface settlements, 8 (or 10) strain gauges for bending moments (SG), and 8 pore pressure transducers (PPT) have been included. Basically, the same set of instruments were used in the layouts of all the tests. The performance of the Cambridge laminar box was specifically studied by Brennan et al [18]. The instrumentation array used in the tests was dictated by the number of channels that can be logged at a sufficiently high sampling rate. This geometrical configuration has been chosen because it is very common in underground constructions. 


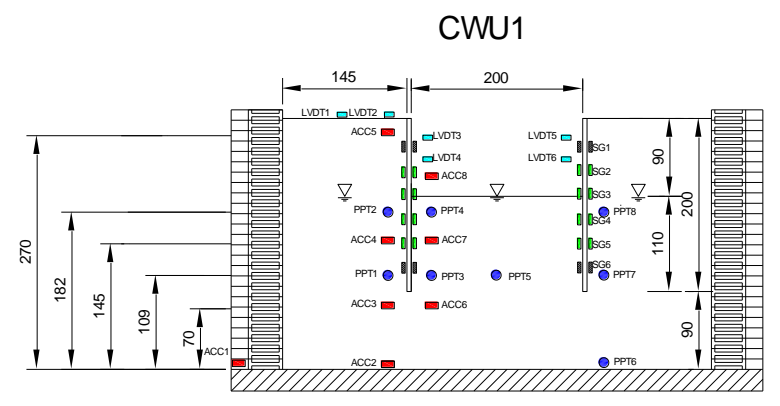

Fig. 2. Layout of instrumentation of test CWU1.

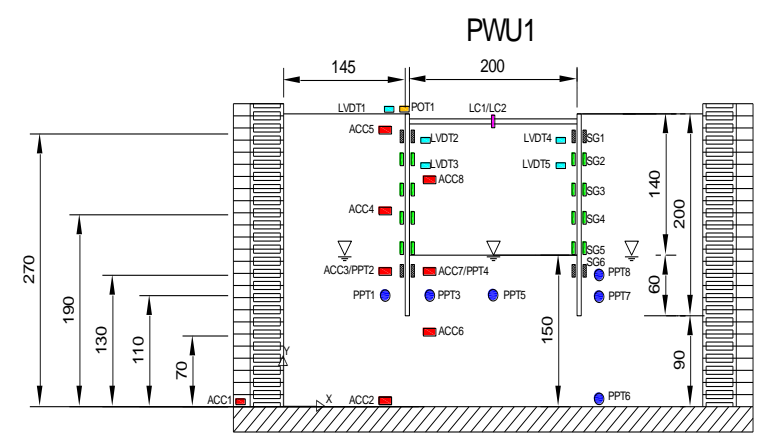

Fig. 3. Layout of instrumentation of test PWU1.

\section{SEISMIC ACTUATOR AND MODEL CONTAINER}

Seismic excitations during centrifuge tests are generated by a Stored Angular Momentum (SAM) actuator developed at Cambridge University [19]. The SAM actuator can apply waves with frequencies in the range 30-50 Hz. Therefore, at the centrifugal acceleration of $40 \mathrm{~g}$, the predominant frequency at prototype scale would be in the range $0.75-1.25 \mathrm{~Hz}$, which can be considered to be in the range of real earthquakes of 1-5 $\mathrm{Hz}$, especially those characterized by a low frequency content close to $1 \mathrm{~Hz}$. To simulate boundary stress and deformation similar to those expected in a finite soil layer with indefinite lateral extent, the models were prepared in a Laminar Box [20], consisting of the superposition of alternating aluminium frames and cylindrical bearings. The Laminar Box has a negligible inertia and is sufficiently stiff in order to not experience very low deformations under high centrifugal accelerations [18]. The internal part of the laminar box is covered by a flexible rubber sheet to avoid losing sand and pore fluid.

\section{MATERIALS AND SATURATION PROCEDURE}

The model retaining walls consisted of aluminium alloy plates with thickness $t=6.36 \mathrm{~mm}$, corresponding to a bending stiffness at prototype scale of $84.5 \cdot 10^{6} \mathrm{Nm}^{2} / \mathrm{m}$ computed with an elastic approach, which is similar to that of a concrete wall constituted by tangent piles with a diameter of $0.45 \mathrm{~m}$. In case of propped walls, two square aluminium rods with an axial stiffness of about $1 \times 10^{6} \mathrm{kN} / \mathrm{m}$ at prototype scale, connected to the walls by cylindrical hinges allowing rotation in the vertical plane, were located at a distance of 195 $\mathrm{mm}$ from each other. A standard fine dry silica sand was used, namely Leighton Buzzard Sand 100/70, fraction $E$, reconstituted at two values of relative density, $D_{r}=38 \%$ and $80 \%$. The specific gravity of the sand is $G_{s}=2.65$, its maximum and minimum voids ratio are equal to 1.014 and 0.613 , respectively, while its constant volume friction angle is $\varphi_{\mathrm{cv}}=32^{\circ}[21,22,23]$.

A high viscosity pore fluid has been used, consisting of a methylcellulose solution, to have a consistent time scale for dynamic and diffusion phenomena [24]. 
The relation of the viscosity of the solution and the concentration of $\operatorname{HPCM}[24,25]$ has been used to compute the mass of HPCM needed to reach a viscosity $N$ times bigger ( $N=40$, in this case) than the viscosity of the water: $v_{20}=6.95 \cdot C^{2.54}$. The models have been saturated under vacuum using an experimental set-up (CAM-Sat) developed at Cambridge University [26] and following a procedure proposed by the authors, described in detail by Tricarico [27].

\section{TESTING PROCEDURES}

At the beginning of each test, the centrifugal acceleration has been increased in four successive steps of 10 $\mathrm{g}$ up to $40 \mathrm{~g}$. Once the testing acceleration of $40 \mathrm{~g}$ has been reached, the first earthquake has been applied at the base of the model. During each test, the model has been subjected to a series of trains of approximately sinusoidal waves with a common nominal frequency $f$, different amplitudes $a_{\max }$, and durations, $t$. After each earthquake a consolidation phase has taken place in order to permit the dissipation of pore pressures generated during the seismic excitation. Tables 2 and 3 show the characteristics of the earthquakes applied in tests respectively on cantilever and propped walls. The choice of the application of a sequence of earthquakes is mainly due to the necessity of optimise the use of the centrifuge facility. From the other side, it is also possible in real cases that a structure is submitted to a sequence of earthquakes.

\begin{tabular}{|c|c|c|c|c|}
\hline Test & Earthquake & $\mathrm{f}(\mathrm{Hz})$ & $a_{\max }(g)$ & Duration (s) \\
\hline \multirow[t]{2}{*}{ CWU1 } & EQ1 & 1.25 & 0.1 & 35 \\
\hline & EQ2 & 1.25 & 0.2 & 35 \\
\hline \multirow[t]{3}{*}{ CWU2 } & EQ1 & 1.25 & 0.075 & 33 \\
\hline & EQ2 & 1.25 & 0.1 & 35 \\
\hline & EQ3 & 1.25 & 0.2 & 35 \\
\hline \multirow[t]{3}{*}{ CWU3 } & EQ1 & 1.25 & 0.11 & 18 \\
\hline & EQ2 & 1.25 & 0.13 & 19 \\
\hline & EQ3 & 1.25 & 0.22 & 19 \\
\hline \multirow[t]{7}{*}{ CWU4 } & EQ1 & 1.25 & 0.11 & 17 \\
\hline & EQ2 & 1.25 & 0.18 & 18 \\
\hline & EQ3 & 1.25 & 0.33 & 18 \\
\hline & EQ4 & 1.25 & 0.11 & 18 \\
\hline & EQ5 & 1.25 & 0.17 & 18 \\
\hline & EQ6 & 1.25 & 0.28 & 18 \\
\hline & EQ7 & 1.25 & 0.33 & 18 \\
\hline
\end{tabular}

Tab. 2. Earthquake characteristics of tests CWU1, CWU2, CWU3 and CWU4 at the prototype scale.

\begin{tabular}{|l|l|l|l|l|}
\hline TEST & Earthquake & $\mathrm{f}(\mathrm{Hz})$ & $\mathrm{a}_{\max }(\mathrm{g})$ & Duration $(\mathrm{s})$ \\
\hline \multirow{3}{*}{ PWU1 } & EQ1 & 1.25 & 0.1 & 35 \\
\cline { 2 - 5 } & EQ2 & 1.25 & 0.2 & 35 \\
\hline \multirow{3}{*}{ PWU2 } & EQ1 & 1.25 & 0.1 & 35 \\
\cline { 2 - 5 } & EQ2 & 1.25 & 0.13 & 35 \\
\cline { 2 - 5 } & EQ3 & 1.25 & 0.25 & 35 \\
\hline \multirow{3}{*}{ PWU3 } & EQ1 & 1.25 & 0.11 & 18 \\
\cline { 2 - 5 } & EQ2 & 1.25 & 0.14 & 18 \\
\cline { 2 - 5 } & EQ3 & 1.25 & 0.33 & 19 \\
\hline
\end{tabular}

Tab. 3. Earthquake characteristic of tests PWU1, PWU2 and PWU3 at the prototype scale.

\section{TEST RESULTS}

\subsection{Accelerations in the soil}


The study of the amplification of the acceleration has been carried out firstly comparing the maximum value of the input acceleration (a_max input) and the maximum value of the acceleration at the soil surface (a_max top). In Figure 4 the a_max input has been placed on the $x$-axis while the a_max top has been placed on the $y$-axis. For each test the maximum acceleration has been determined from the acceleration data given of the accelerometer at the base of model container (Acc1 in all tests layout) and the accelerometer near the soil surface. It is evident that a strong de-amplification has taken place in tests in loose sand, especially at the highest values of input acceleration, while only marginal changes in the maximum values were observed in tests with dense sand.

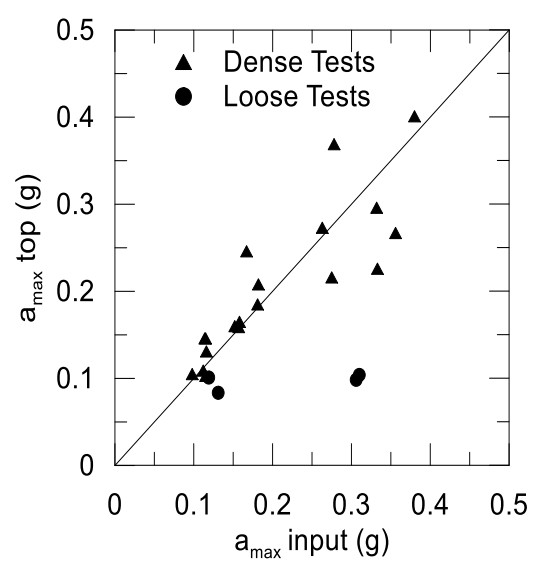

Fig. 4. Amplification of acceleration, comparison between maximum input acceleration and maximum top acceleration.

The same comparison, carried out by Conti [6] for tests in dry sand on similar walls (both, cantilever or with one-prop) in the same soil (both loose and dense), shows that a significant amplification of acceleration occurred. In Figure 5 the plot in Figure 4 has been completed with the data of the tests of Conti [6]. This suggests that a significantly different behaviour of the soil structure system occurs in terms of amplification in dry sand relative to saturated sands particularly in the upper part of the plot i.e. at higher input accelerations. This is to be expected as the saturated soil models can generate excess pore pressures leading to softening in the soil response where as dry sand models can amplify the input accelerations.

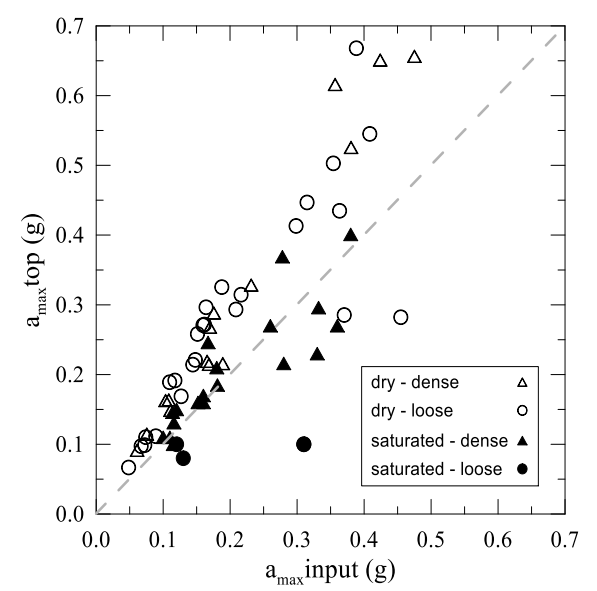

Fig. 5. Amplification of acceleration, comparison between tests in saturated sand (present work) and tests in dry sand [5].

\subsection{Excess pore pressures in the soil}

The excess pore pressure at a given depth of the soil deposit can be represented by the pore pressure coefficient, $r_{u}$, defined as the ratio between the increase $\Delta u$ of the pore pressure $u$ induced by the seismic 
excitation and the initial vertical effective stress $\sigma_{v 0}^{\prime}$ computed assuming a geostatic stress distribution. In Fig. 6 and in Fig. 7 the excess pore pressure trend expressed as the $r_{u}$ coefficient is presented, with reference to the pairs of test CWU1-CWU2 and PWU1-PWU2. CWU1 and CWU2 are tests on cantilever walls respectively in loose sand and in dense sand, while PWU1 and PWU2 are tests on propped walls respectively in loose sand and in dense sand. In this way, for each figure, a single structure configuration is selected and thus the difference of the response is only due to the different relative density of soil model. For each figure, the left column is devoted to the last earthquake of the first test (EQ2 for test CWU1 and EQ2 for test PWU1) while the second one is related to the last earthquake of the second test (EQ3 for test CWU2 and EQ3 for test PWU2). In the top row the input acceleration is shown while the following three rows report the PPTs results subdivided into PPTs at the back of the left wall (second row), at the excavated side (third row) and at the back of the right wall (last row from the top). In each diagram, the pore pressure coefficient, $r_{u}$, is compared with unity, which corresponds to full liquefaction. It is evident that in all the cases the $r_{u}$ coefficient is far below unity at the back sides of the walls, while it reaches values close to one in the excavated side, irrespective of the relative density of the soil. Consequently, on the basis of the values of the $r_{u}$ coefficient, the condition of liquefaction should be achieved in both cases between the walls. Besides this, experimental evidences, like the presence of sand boils at the end of the test PWU1 (Fig. 8), in loose sands, at the soil surface of the excavated side, confirm the occurrence of liquefaction. It is also interesting to see that in one case PPT5 between the walls records an $r_{u}>1$ (CWU1-EQ2). This is due to the movement of this instrument downwards as the soil between the walls has fully liquefied. In dense sand models the $r_{u}$ values remain below unity. These findings explain why a strong de-amplification of the acceleration has been observed in loose sand tests, since it is related to the decrease of the soil stiffness due to the decrease of the effective stresses.

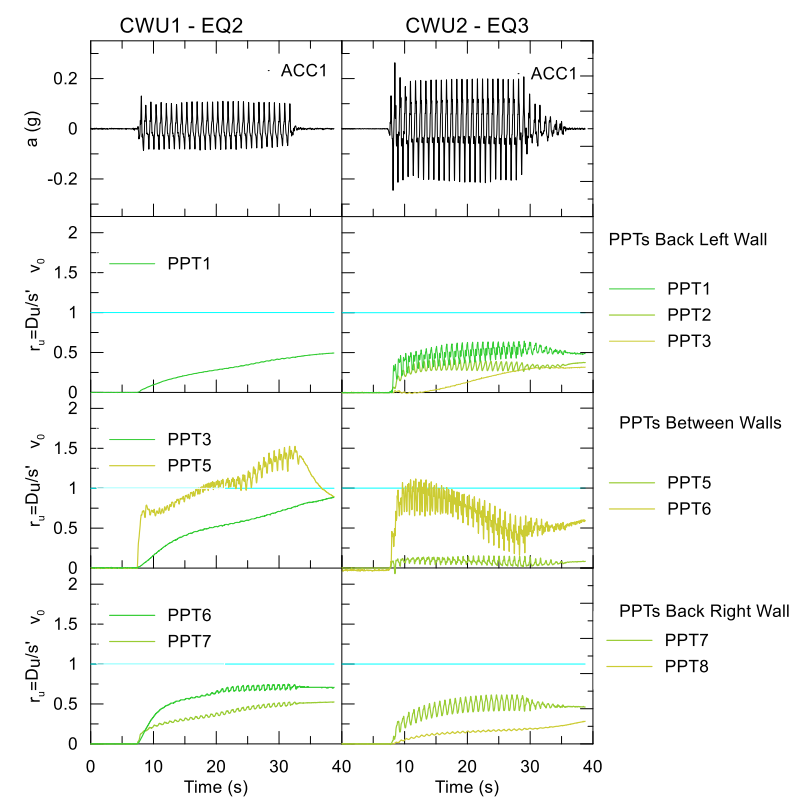

Fig. 6. $r_{\mathrm{u}}$ coefficient in tests CWU1 and CWU2. 


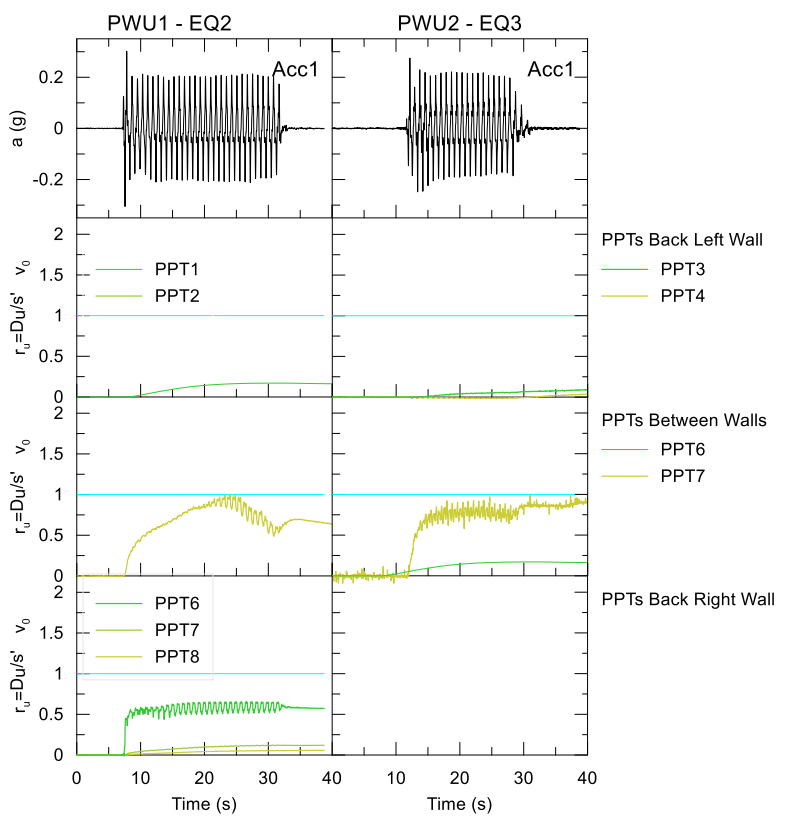

Fig. 7. $r_{\mathrm{u}}$ coefficient in tests PWU1 and PWU2.

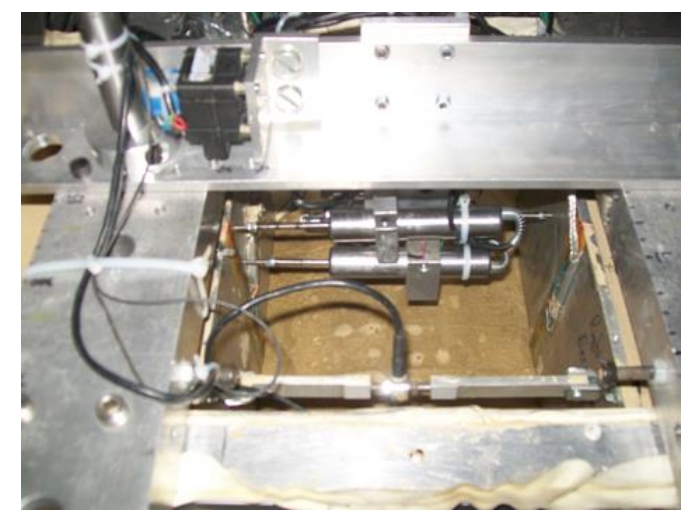

Fig. 8 Sand boils observed at the end of test PWU1 at the excavated side.

\subsection{Lateral displacement of walls}

With regards to the displacements of the walls, it is worth emphasising that the displacement plots are not the direct plot of the measured displacements, since these are affected by the residual movement of the laminar box rings. To this regard, Tricarico [27] proposed a procedure to reduce the influence of the rings displacements on the measurements of the LVDTs.

Figure 12 highlights the walls static configuration and at the end of the earthquakes (residual) of the tests CWU1, PWU1, CWU2 and PWU2. As regards the former, it is interesting to observe the distinction between the responses in test CWU1 and test CWU2. In fact, considering the test CWU1 (loose sand), the configuration of the walls at the end of the earthquakes, compared with that one in static conditions, is close to the vertical (EQ2) or it suggests a counter-rotation being the toes of the walls closer than the tops (EQ1). Such behaviour can be directly attributed to the strong loss of resistance in the excavated side due to the occurrence of liquefaction. On the other hand in test CWU2 (dense sand), the subsequent configurations of the walls, passing from the static one to the residual ones, suggest a progressive accumulation of displacement at the top of the walls. This experimental finding suggests that actually only in test CWU1 liquefaction conditions have been reached. The collapse mechanism in tests PWU1 and PWU2 is represented by a rotation of the walls around the props and, in this regard, there is no a direct evidence 
of the occurrence of liquefaction, since the collapse mechanism is qualitatively the same whether the loose sand test or the dense sand test is considered. As regards the entity of the accumulated displacements, it is around $0.3 \mathrm{~m}$ at the top of the walls for tests CWU1 and CWU2, while it is about $0.2 \mathrm{~m}$ at the bottom of the walls for tests PWU1 and PWU2.
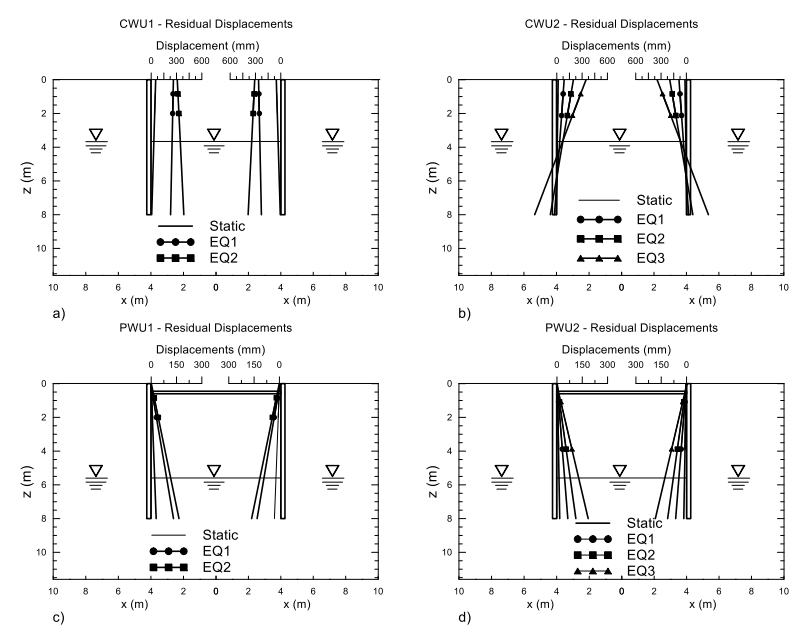

Fig. 12. Residual displacements in tests CWU1 (a), CWU2 (b), PWU1 (c), PWU2 (d).

Also for the displacements it is interesting to compare the response of the present tests with those carried out in dry sands [6]. In Table 4 such comparison is presented with respect the accumulated displacements at the top of the cantilever walls and at the bottom of the propped walls at the prototype scale. The accumulated displacements for tests performed in saturated sand are much higher than those in dry sand.

\begin{tabular}{|l|l|l|l|}
\hline & Test name & $\begin{array}{l}\text { Top Displ. } \\
(\mathrm{mm})\end{array}$ & $\begin{array}{l}\text { Bottom } \\
\text { Displ. (mm) }\end{array}$ \\
\hline Cantilever walls - saturated sand & CWU1 & 309 & $/$ \\
& CWU2 & 346 & $/$ \\
\hline Cantilever walls - dry sand [5] & CW1 & 90 & $/$ \\
\hline Propped walls - saturated sand & PWU1 & $/$ & 206 \\
& PWU2 & $/$ & 184 \\
\hline Propped walls - dry sand (Conti, 2010) & PW2 & $/$ & 100 \\
\hline
\end{tabular}

Tab. 4. Comparison between accumulated displacements in saturated tests and those in dry sand tests at prototype scale [5].

\subsection{Bending moments in the walls}

An example of the distribution of the bending moment is depicted in Figure 13 relatively to tests CWU1 and CWU2. The value of the bending moment at the strain gauge where it is maximum at the end of the swing up is reported in Table 5 for each earthquake of the tests. 

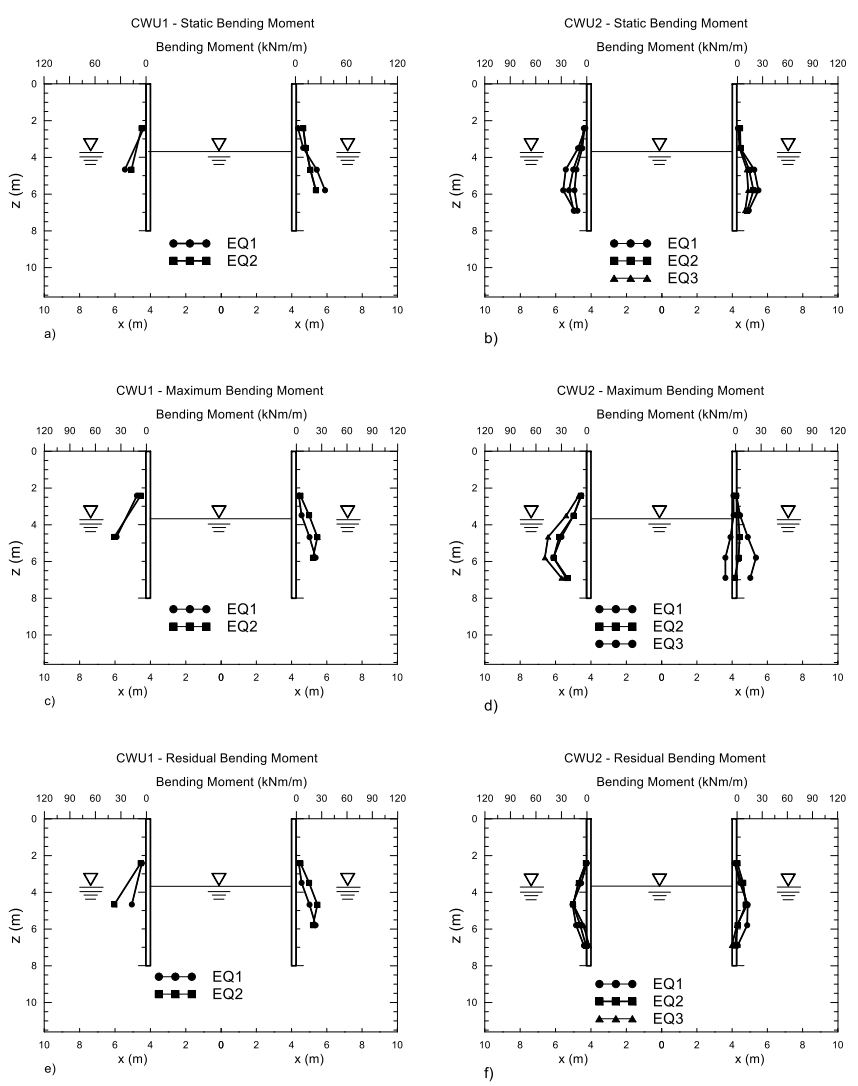

Fig. 13. Bending moment in tests CWU1 (a), c), e)) and CWU2 (b), d) and f)).

The values of the bending moment are relative to selected time instants of the earthquakes, namely instant 1 , that is the time instant before the earthquake, also called pre-EQ; instant 2, that is the time instant when the bending moment reaches its maximum value; instant 3 , that is the time instant measured immediately after the shaking, also called short term residual; instant 4, that is the time instant after the complete dissipation of the excess pore pressure generated during the earthquake, also called long term residual (Tab.6).

\begin{tabular}{|c|c|c|c|c|c|}
\hline Test/SG & & $\begin{array}{l}\text { pre-EQ } \\
(\mathrm{kNm} / \mathrm{m})\end{array}$ & $\begin{array}{l}\text { Max. } \\
(\mathrm{kNm} / \mathrm{m})\end{array}$ & $\begin{array}{l}\text { Short } \\
\text { Term Res. } \\
(\mathrm{kNm} / \mathrm{m})\end{array}$ & $\begin{array}{l}\text { Long } \\
\text { Term Res. } \\
(\mathrm{kNm} / \mathrm{m})\end{array}$ \\
\hline CWU1/SG4 & $\begin{array}{l}\text { EQ1 } \\
\text { EQ2 }\end{array}$ & $\begin{array}{l}35 \\
23\end{array}$ & $\begin{array}{l}38 \\
24\end{array}$ & $\begin{array}{l}9 \\
10\end{array}$ & $\begin{array}{l}23 \\
19\end{array}$ \\
\hline PWU1/SG4 & $\begin{array}{l}\text { EQ1 } \\
\text { EQ2 }\end{array}$ & $\begin{array}{l}76 \\
65\end{array}$ & $\begin{array}{l}86 \\
94\end{array}$ & $\begin{array}{l}33 \\
-16\end{array}$ & $\begin{array}{l}64 \\
56\end{array}$ \\
\hline CWU2/SG5 & $\begin{array}{l}\text { EQ1 } \\
\text { EQ2 } \\
\text { EQ3 }\end{array}$ & $\begin{array}{l}27 \\
22 \\
15\end{array}$ & $\begin{array}{l}39 \\
39 \\
49\end{array}$ & $\begin{array}{l}12 \\
8 \\
4\end{array}$ & $\begin{array}{l}22 \\
15 \\
-12\end{array}$ \\
\hline PWU2/SG4 & $\begin{array}{l}\text { EQ1 } \\
\text { EQ2 } \\
\text { EQ3 }\end{array}$ & $\begin{array}{l}42 \\
64 \\
75\end{array}$ & $\begin{array}{l}86 \\
107 \\
130\end{array}$ & $\begin{array}{l}71 \\
79 \\
89\end{array}$ & $\begin{array}{l}66 \\
77 \\
89\end{array}$ \\
\hline
\end{tabular}

Tab. 5. Bending moment at prototype scale measured in tests CWU1, PWU1, CWU2 and PWU2 at a specific strain gauge.

Indicating with EQi the i-th earthquake, with EQi(j) the j-th time instant of the i-th earthquake and with MEQi(j) the bending moment relative to EQi(j) (Tab.6), it is observed that: 


\begin{tabular}{|l|l|l|l|l|}
\hline M[EQi(j)] & Pre-EQ & Maximum & $\begin{array}{l}\text { Short } \\
\text { Term } \\
\text { Residual }\end{array}$ & $\begin{array}{l}\text { Long } \\
\text { Term } \\
\text { Residual }\end{array}$ \\
\cline { 2 - 5 } & Instant 1 & Instant 2 & Instant 3 & Instant 4 \\
\hline EQ1 & $\begin{array}{l}\text { MEQ1(1) } \\
\text { (end of } \\
\text { swing up) }\end{array}$ & MEQ1(2) & MEQ1(3) & MEQ1(4) \\
\hline EQ2 & MEQ2(1) & MEQ2(2) & MEQ2(3) & MEQ2(4) \\
\hline EQ3 & MEQ3(1) & MEQ3(2) & MEQ3(3) & MEQ3(4) \\
\hline
\end{tabular}

Tab. 6. Time instants chosen for the observations on the Bending Moment.

1. For a given type of structure, the MEQ1(1), that is the bending moment at the end of the swing up, is higher for the walls installed in loose sand than for those installed in dense sand. For instance, MEQ1(1) for test CWU1 (cantilever - loose sand) is $35 \mathrm{kNm} / \mathrm{m}$ while for CWU2 (cantilever - dense sand) is 27 $\mathrm{kNm} / \mathrm{m}$ and for test PWU1 (propped - loose sand) is $76 \mathrm{kNm} / \mathrm{m}$ while for test PWU2 is $42 \mathrm{kNm} / \mathrm{m}$ (propped-dense sand);

2. A strong decrease of the bending moment took place during the earthquakes of the tests CWU1, PWU1 and CWU2 leading to low values of the short term residual bending moment. In fact, the quantity $\Delta \operatorname{Res}(\%)=\{$ MEQi(3)/MEQi(1)-1 $\} \times 100$

which is the percentage of variation of the short term residual bending moment with respect to its value before the earthquake of the $i$-th earthquake, relative to those tests, is -75\% and $-56 \%$ for EQ1 and EQ2 of CWU1, $-56 \%$ and $-124 \%$ for EQ1 and EQ2 of PWU1 and $-55 \%,-63 \%$ and $-73 \%$ for EQ1, EQ2 and EQ3 of test CWU2 (Table 7). On the other hand, an increase of the bending moment took place during the earthquakes of test PWU2 being $\triangle$ Res equal to $+69 \%,+23 \%$ and $+18 \%$ for EQ1, EQ2 and EQ3 of test PWU2 (Table 7);

3. In test CWU1 MEQ1(1)>MEQ2(1), in test PWU1 MEQ1(1)>MEQ2(1) and in test CWU2 MEQ1(1)>MEQ2(1)>MEQ3(1) while in test PWU2 MEQ1(1)<MEQ2(1)<MEQ3(1);

4. The quantity

$\Delta \operatorname{Max}(\%)=\{$ MEQi(2)/MEQi(1)-1 $\} \times 100$

which is the percentage of variation of the maximum bending moment with respect to its pre-EQ value of the $\mathrm{i}$-th earthquake, is higher in tests in dense sand than in loose sand for a given structure typology. For cantilever walls $\triangle \mathrm{Max}$ is $+8 \%$ and $+4 \%$ in test CWU1 for EQ1 and EQ2, while it is $+44 \%,+77 \%$ and $+226 \%$ in test CWU2. For propped walls the increase is of $+13 \%$ and $+44 \%$ in EQ1 and EQ2 of test PWU1 and it is $+104 \%,+69 \%$ and $+73 \%$ in EQ1, EQ2 and EQ3 of test PWU2 (Tab. 7 ).

\begin{tabular}{|l|l|l|l|}
\hline & & $\boldsymbol{\Delta}_{\text {Res }}(\%)$ & $\boldsymbol{\Delta}_{\text {Max }}(\%)$ \\
\hline CWU1 & EQ1 & $-75 \%$ & $8 \%$ \\
& EQ2 & $-56 \%$ & $4 \%$ \\
\hline PWU1 & EQ1 & $-56 \%$ & $13 \%$ \\
& EQ2 & $-124 \%$ & $44 \%$ \\
\hline CWU2 & EQ1 & $-55 \%$ & $44 \%$ \\
& EQ2 & $-63 \%$ & $77 \%$ \\
& EQ3 & $-73 \%$ & $226 \%$ \\
\hline PWU2 & EQ1 & $+69 \%$ & $104 \%$ \\
& EQ2 & $+23 \%$ & $69 \% 73 \%$ \\
& EQ3 & $+18 \%$ & \\
\hline
\end{tabular}


Tab. 7. Percentage of variation of the residual bending moment and the maximum bending moment with respect their pre-EQ values.

It could be of interest to try to justify the experimental evidence in points 1 to 4 :

- Point 1: the higher value of the bending moment at the end of the swing up in tests in loose sand with respect to the tests in dense sand is directly related to the difference in the relative density of the tests resulting in a higher value the earth pressure on the wall;

- Point 2: the low values of short term residual bending moment in tests CWU1, PWU1 and CWU2 are likely related to the strong loss of shearing resistance in the portion of soil below the water table as a consequence of the pore pressure increase; such strong loss does not occur in test PWU2, even if an increase of the pore pressure has been observed, and a progressive accumulation of the bending moment has taken place. Such difference can be related to the tendency of the loose sand soils (tests CWU1 and PWU1) to compact and eventually to exhibit excess pore pressures and liquefy when the volumetric strains are inhibited and, on the other hand, of dense sand soils to dilate and not liquefy (PWU2). Test CWU2 shows low values of short term residual bending moment despite its high relative density; this finding is probably due to lower value of relative density in the model construction (sand pouring procedures and saturation) if compared with the expected one;

- Point 3: the progressive decrease of MEQi(1) in tests CWU1, PWU1 and CWU2 or its progressive accumulation in test PWU2 reflect the fact that, in the former, there is not a full recovery of the bending moment after its strong decrease that occurred during the earthquake, while, in the latter, a progressive mobilization of the passive resistance has taken place with a consequent increase of MEQi(1);

- Point 4: the higher percentages of variation of the maximum bending moment with respect its pre-EQ value if compared with those in loose sand are a direct consequence of the difference in the relative density, which determines a significant difference in the inertia forces.

Finally, a comparison between the bending moment in tests in saturated sand and those in dry sand [6] is presented in Table 8 in terms of the maximum values of the bending moment for the different time instants called static, maximum and residual. For the last one the long term residual value in the tests in saturated sand has been considered useful for the comparison. The values outline a higher bending moment in tests in dry sand with respect those in saturated sand especially considering the maximum and the residual bending moment.

\begin{tabular}{|c|c|c|c|c|}
\hline Test & & $\begin{array}{l}\text { Static } \\
(\mathrm{kNm} / \\
\mathrm{m})\end{array}$ & $\begin{array}{l}\text { Max. } \\
(\mathrm{kNm} / \mathrm{m})\end{array}$ & $\begin{array}{l}\text { Residual } \\
(\mathrm{kNm} / \mathrm{m})\end{array}$ \\
\hline CW1 $\left(D_{r}=84 \%\right)$ & Dry & 35 & 88 & 69 \\
\hline $\begin{array}{l}\text { CWU1 }\left(D_{r}=38 \%\right) \\
\left.\text { CWU2 ( } D_{r}=88 \%\right)\end{array}$ & $\begin{array}{l}\text { Sat. } \\
\text { Sat. }\end{array}$ & $\begin{array}{l}35 \\
27\end{array}$ & $\begin{array}{l}38 \\
49\end{array}$ & $\begin{array}{l}23 \\
22\end{array}$ \\
\hline $\begin{array}{l}\text { PW1 }\left(D_{r}=78 \%\right) \\
\left.\text { PW2 ( } D_{r}=42 \%\right)\end{array}$ & $\begin{array}{l}\text { Dry } \\
\text { Dry }\end{array}$ & $\begin{array}{l}45 \\
45\end{array}$ & $\begin{array}{l}120 \\
140\end{array}$ & $\begin{array}{l}90 \\
110\end{array}$ \\
\hline $\begin{array}{l}\text { PWU1 }\left(D_{r}=38 \%\right) \\
\left.\text { PWU2 ( } D_{r}=88 \%\right)\end{array}$ & $\begin{array}{l}\text { Sat. } \\
\text { Sat. }\end{array}$ & $\begin{array}{l}76 \\
75\end{array}$ & $\begin{array}{l}94 \\
130\end{array}$ & $\begin{array}{l}64 \\
89\end{array}$ \\
\hline
\end{tabular}

Tab. 8. Bending moment at prototype scale of tests in dry sand [5] on cantilever walls (CW1) and propped walls (PW1).

\section{Measurement of tactile pressure sensor}

In tests CWU3, CWU4 and PWU3 an ultrathin tactile pressure sensor Tekscan has been glued onto the left wall in order to measure the total earth pressure acting on active side and passive side. The tactile pressure 
sensors were calibrated using the procedure outlined by Kirkwood [28]. The results of the measurements obtained by means of these sensors are included in this paper to provide qualitative assessment of the earth pressure distribution in the two types of retaining walls studied. Figures 14 and 15 show the results of the measurements obtained by the Tekscan pressure sensor at the end of the three earthquakes applied during the tests CWU3 and PWU3. In both the figures, three important features can be highlighted: i) the progressive accumulation of the total horizontal stress acting on both active and passive sides of the walls; ii) above the excavation level a very low pressure is acting on the active side and above the water table, especially in test CWU3; this can be explained [27] considering a possible reduction in the active thrust due to the suction inducted by the capillary rise of the methylcellulose; iii) the average slope of the diagram below the water table, which shows some uncertainties on the absolute values of the total earth pressure as $10 \mathrm{kN} / \mathrm{m}^{3}$, which is the minimum slope that the diagram, should have below the excavation level because of the presence of the methyl cellulose. This might indicate either a malfunction of the pressure sensor during the test, probably caused by the vacuum applied during the saturation procedure or an issue with the calibration of the instrument.

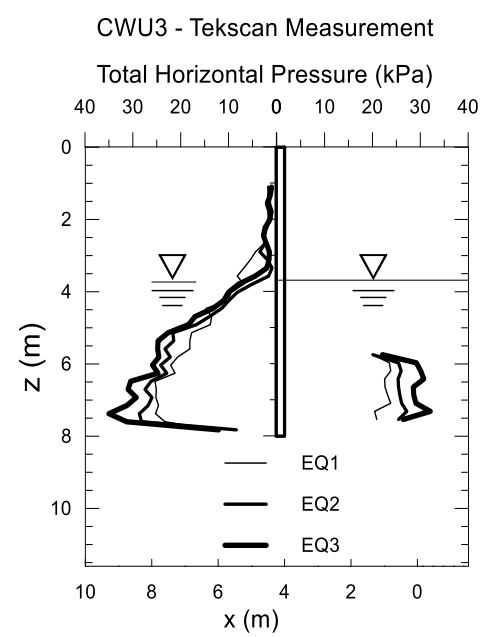

Fig. 14. Test CWU3: total horizontal pressure distribution obtained from Tekscan measurement.

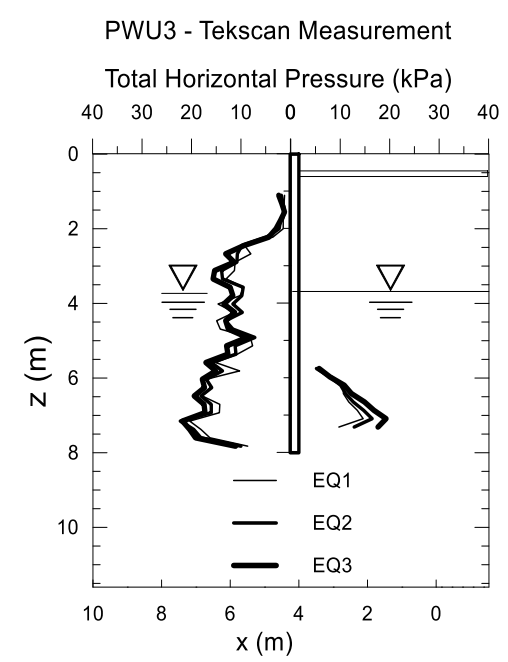

Fig. 15. Test PWU3: total horizontal pressure distribution obtained from Tekscan measurement.

\section{CONCLUSIONS}


The results of an experimental series that constituted of seven dynamic centrifuge tests on pair of cantilevered and propped retaining walls embedded in saturated sand have been discussed in their most relevant points: amplification of the acceleration in the soil, pore pressure trend during the earthquakes expressed by means of the $r_{u}$ coefficient, accumulated displacements of the walls, characteristics of the collapse mechanism, bending moments at different time instants and comparison with similar tests in dry sand. Finally the data derived from the pressure sensor measuring the total pressure acting on the left wall of the models CWU3 and PWU3 have been presented as distribution of the average horizontal total stress with respect to the width of the wall of the measured total pressure. Moreover, the comparison of the test results in terms of pore pressures, displacements and bending moment has shown a good agreement between tests with similar geometries and relative density of the sand. The generation of pore pressures, irrespective of the relative density of the soil, determines a significant accumulation of permanent displacements, while the structure is less stressed with respect the dry case with similar geometry; thus soil treatment may be considered as an option to reduce the accumulation of displacements. These results have also an indirect effect on design since these results can be back-analyses by theoretical models of different complexity in order to verify their capability to interpret the observed behaviour and to predict the behaviour of real structures. Further investigations of the soil-structure system in case of soil treatment are needed both in terms of accumulated displacements and structure resistance.

\section{ACKNOWLEDGEMENTS}

The first four tests have been performed under the SERIES project 2007-2014 and the other three tests have been performed under the ReLUIS project.

\section{References}

[1]. Bureau of Ports and Harbors (1989): Earthquake Resistant Design for Quay Walls and Piers in Japan. Ministry of Transport, Tokyo, Japan.

[2]. lai S. and Kameoka T. (1993): Finite Element Analysis of Earthquake Induced Damage to Anchored Sheet Pile Quay Walls. Soils Foundations, 33(1), 71-91.

[3]. Kamon M., Wako T., Isemura K., Sawa K., Mimura M., Tateyama K., Kobayashi S. (1996): Geotechnical Disasters on the Waterfront. Soils Foundations, Special Issue, January, pp. 137-147.

[4]. Sitar N., Geraili Mikola R., and Candia G. "Seismically Induced Lateral Earth Pressures on Retaining Structures and Basements Walls", Keynote Lecture, Geotechnical Engineering State of the Art and Practice, Keynote Lectures from GeoCongress 2012, GSP 226, ASCE, 2012.

[5]. Aversa S., de Sanctis L., Maiorano RMS., Tricarico M., Viggiani G.M.B. (2015): Centrifuge Modeling of Retaining Walls Embedded in Saturated Sand under Seismic Actions. Springer International Publishing, Book: Experimental Research in Earthquake Engineering, pp. 543-562.

[6]. Conti R. (2010): Modellazione Fisica e Numerica del Comportamento di Opere di Sostegno Flessibili in Condizioni Sismiche. PhD Thesis, University of Tor Vergata, Rome, Italy.

[7]. Conti R., Madabhushi S.P.G., Viggiani G.M.B. (2012): On the Behaviour of Flexible Retaining Walls under Seismic Actions. Géotechnique, 62(12), 1081-1094.

[8]. Dashti S., Hushmand A., Ghayoomi, M., McCartney J. S., Zhang M., Hushmand B., Mokarram N., Bastani A., Davis C., Yangsoo L., Hu, J. (2013). "Centrifuge Modeling of Seismic Soil-StructureInteraction and Lateral Earth Pressures for Large Near-Surface Underground Structures", Proceedings of the 18th International Conference on Soil Mechanics and Geotechnical Engineering, Paris, France. 
[9]. Dewoolkar M. M., Ko H. Y., and Pak R.Y.S., (2001): Seismic Behaviour of Cantilever Retaining Wall with Liquefiable Backfills. Journal of Geotechnical and Geoenvironmental Engineering 127(5), 424434.

[10]. Nakamura S. 2006. Re-examination of Mononobe-Okabe Theory of Gravity Retaining Walls using Centrifuge Model Tests. Soils and Foundations 46(2): 135-146.

[11]. Zeng X. (1998): Seismic Response of Gravity Quay Walls I, Centrifuge Modeling. Journal of Geotechnical and Geonvironmental Engineering, 124(5), 406-417.

[12]. Zeng X., Steedman, R.S. (1993): On the Behavior of Quay Walls in Earthquakes. Géotechnique, 43(3), 417-431.

[13]. Matsusawa H., Ishibashi I., Kawamura M., (1984): Dynamic Soil and Water Pressures of Submerged Soils. Journal of Geotechnical Engineering, 111 (10), 1161-1176.

[14]. Westergaard H. M. (1933): Water Pressures on Dams during Earthquake. Transaction of ASCE, 98(2), pp.418-433.

[15]. Madabhushi S.P.G., Zeng X., (2007): Simulating Seismic Response of Cantilever Retaining Walls., Journal of Geotechnical and Geonvironmental Engineering, ASCE, 133(5), pp, 539-549.

[16]. Madabhushi S.P.G., Houghton N.E. \& Haigh S.K. (2006): A New Automatic Sand Pourer for Model Preparation at University of Cambridge. International Conference on Physical Modeling in Geotechnics, the Hong Kong University of Science and Technology, Hong Kong.

[17]. Ortiz L.A., Scott R.F., Lee J. (1983): Dynamic Centrifuge Testing of a Cantilever Retaining Wall. Earthquake Engineering \& Structural Dynamics. Vol. 11(2) pp. 251-268.

[18]. Brennan A.J.; Madabhushi S. P. G.; Houghton N. E. (2006): Comparing laminar and equivalent shear beam (ESB) containers for dynamic centrifuge modeling. In Proceedings 6th International Conference on Physical Modelling in Geotechnics, pp. 171-176.

[19]. Madabhushi S.P.G., Schofield A.N. \& Lesley S. (1998): A New Stored Angular Momentum (SAM) Based Earthquake Actuator. International Conference on Centrifuge Modeling, Tokyo, Japan: 111-116.

[20]. Knappett J.A. (2006): Piled Foundations in Liquefiable Soils: accounting for axial loads. PhD Thesis, Cambridge University, England.

[21]. Tan F. S. C. (1990): Centrifuge and Theoretical Modelling of Conical Footings on Sand. PhD Thesis, Cambridge University, England.

[22]. Jeyatharan K. (1991): Partial Liquefaction of Sand Fill in a Mobile Arctic Caisson under Dynamic IceLoading: PhD Thesis, University of Cambridge, UK.

[23]. Visone C., Santucci de Magistris F. (2009): Mechanical Behaviour of the Leighton Buzzard Sand 100/170 under Monotonic, Cyclic and Dynamic Loading Conditions. Proceedings of the XIII ANIDIS Conference 2009 "L'Ingegneria Sismica in Italia" (Editors Franco Braga and Marco Savoia), Bologna, Italy, June, 28/2009 - July, 7/2009, DVD Paper S7.23, IMREADY, ISBN 978-88-904292-0-0.

[24]. Stewart D.P., Chen Y-R and Kutter B.L.: Experience with the Use of Methycellulose as Viscous Pore Fluid in Centrifuge Models, 1998. Geotechnical Testing Journal, 21(4), pp. 365-369.

[25]. Adamidis O. and Madabhushi S.P.G., (2015): Use of viscous pore fluids in dynamic centrifuge modeling. International Journal of Physical Modelling in Geotechnics, 15(3), pp. 141-149.

[26]. Stringer M.E and Madabhushi S.P.G., 2009: Novel Computer Controlled Saturation of Dynamic Centrifuge Models using High Viscosity Fluids. Geotechnical Testing Journal, 32(6), pp.559-564. 
[27]. Tricarico M., (2015): Centrifuge Modelling of Flexible Retaining Walls in Saturated Sand under Seismic Actions. PhD Thesis, Federico II University of Naples, Italy.

[28]. Kirkwood, P. B. (2015) Cyclic lateral loading of monopile foundations in sand, PhD thesis, University of Cambridge, UK. 